\title{
Language of Music and Its Psychophysicat Foundations (Review)
}

DOI: $10.17691 / \mathrm{stm} 2019.11 .1 .04$

Received October 22, 2018

M. Korsakova-Kreyn, PhD, Associate Professor, Psychology

The Touro College and University System, Lander College for Women, 227 West 60th St., New York, NY 10023, USA

Application of music in rehabilitation medicine requires an understanding of the mechanisms of music perception. This article discusses differences in character of the basic melodic elements and addresses some of the specifics of tonal space. Colloquially, music is called the language of emotion. Bearing in mind that high-level cognitive functioning in humans is inseparable from affective consciousness, investigating the mechanisms of emotional processing belongs to an important area of cognitive sciences. Studying music perception can help to advance methods of music therapy and to elucidate major aspects of human consciousness.

Key words: neurophysiological correlates of musical perception; mechanisms of music perception; music therapy.

Music is the shaping of the invisible. Leonardo da Vinci

\section{Introduction}

According to imaging studies, music can activate the biological reward system [1, 2] and cause goosebumps (piloerection) [3, 4]. Music can affect the psychophysiological states of the listeners by influencing their neurochemistry [5], heart rate, respiratory rate, and electroconductivity of skin [6-10]. Whereas pragmatic emotions [11, 12] have survival value and occur in response to specific signs and images, the emotional responsiveness to music is difficult to explain since music has neither cognitive constants [13] that are comparable to words and visible images nor specific somatosensory sensations such as the warmth of a fire or the wetness of rain.

The ability of music to influence the physiology of listeners and to evoke complex emotions [14] without the involvement of familiar words and recognizable visual images means that music uses some simple and at the same time powerful mechanisms of communication that reach the human mind rather directly.

\section{Psychophysics of consonance and dissonance and the principle of least effort}

The main melodic elements of music - the pleasing consonances and tense dissonances - produce different patterns of brain activation in newborns [15]. The heart rate of one-month-old babies changes for those melodies that the babies heard before birth, during last month of their mothers' normal pregnancy [16]. Studies with 2-4-month-old babies show that the babies look with interest at the source of consonances and turn away when they hear dissonant sounds [17]. In other words, the understanding of the character of the main melodic elements of music is available to human beings in infancy. By the age of eight, children develop an intuition for the language of tonal harmony [18], which makes the navigation in a tonal space of music entirely accessible. A study with young adults' reactions to different musical styles and different degrees of tonal modulation (reorientation of a scale from one tonal center to another in the tonal space) reveals that people with no formal musical education have a finetuned sensitivity to complex musical processes [19]. Understanding the essence of music's content does not require special musical training [20].

Music perception belongs to affective consciousness [21, 22]; according to a model of the triune brain [23], the processes of pre-linguistic and emotional awareness are carried out in the limbic system [24]. Studies of emotional processing in music focus primarily on the tonal relationships $[25,26]$, namely on such aspects of music as the major and minor modes [19, 27-37]. In musicology, the tonal relationships are explained in terms of the hierarchy of perceived tonal tension and tonal instability [38-41]. Intuitive anticipation of tonal instability resolving into tonal stability is the source of a sense of movement in music [39, 42].

The concept of tonal instability applies to the explanation of the basics of music theory and such structural aspect as musical phrasing to beginner students. Furthermore, the concept of tonal instability is essential for theoretical work on musical syntax

Corresponding author: Marina Korsakova-Kreyn, e-mail: mnkors@gmail.com 
(functional harmony) [25, 41] and the analysis of musical forms $[40,43,44]$. Because perceived tonal instability is generated by the hierarchy of tonal attraction, or by the gradient of attraction, tonal space is defined as a space of "phenomenal gravity" [45].

One of the directions in the research in music perception concerns a link between perceived tonal tension and real physical tension [46-48]; this link allows us to attribute music perception to a field of embodied cognition [42, 49, 50]. On the other hand, the discovery of the gradient of perceptual comfort for combinations of musical sounds $[51,52]$ makes it possible to explain the difference between dissonances and consonances in terms of the principle of least effort [53]. Namely, since sounds that make consonant compounds share important spectral information [54], the sharing most likely facilitates the neural processing of consonant compounds as compared to dissonant compound. Here we are talking about the overtone series generated by vibration [55].

The commonality of important spectral information is particularly obvious for the Pythagorean intervals of the octave, fifth, and fourth. In each of the Pythagorean intervals, the second tone duplicates one of the strongest overtones of the first tone (accounting for the octave equivalence). Even more impressive is the psychophysics of a triad in a major mode. The "happy" major triad consists of the fundamental tone and its first four overtones. (This also means that overtone series of any naturally produced musical sound begins with a major triad). Apparently, with regard to the basic melodic elements we are dealing with the "law of laziness" when the processing of a complex auditory signal is facilitated by duplication of important information in overtone series of the constituent tones, this translates into pleasant sonic sensation. This resonates with Leibniz's claim that music is "unconscious arithmetic". The perception of melodic elements does not require intellectual efforts, but relies on the unconscious calculations within the "hidden dimension" of overtones.

The link between perceived tonal tension and real physical tension [47], as well as the discovery of the gradient of perceptual comfort for combinations of musical sound [51, 52], emphasize the importance of precognitive aspect of music perception. The intuitive understanding of the basic melodic elements explains the broad availability of music to different groups of people, including Alzheimer's patients [56] and teenagers with autism [57].

\section{Archaic model of music perception}

The link between perceived tonal tension and real physical tension means that the tonal-temporal patterns of music convey the logic of emotions [58] using the most primitive reactions inherent in all living organisms physical tension and relaxation. In the context of affective neuroscience [22], the archaic model of music perception [19] proposes that emotions in music are closely related to visceromotor responses to the tense and not-tense ("relaxed") melodic elements. Specifically, the archaic model of music perception postulates that the integration of tonal-temporal relationships in music imitates the dynamics of integration of somato- and visceromotor information inherent in the formation of usual nonmusical emotions and that this "internal" somato- and visceromotor information is essential to shaping musical structures that convey images of psychological time.

When comparing the mechanisms of information transfer in music with the mechanisms of information transfer in speech, we face a striking difference. Music has neither words nor parts of speech. Instead, the perception of music is based on an intuitive sense of the degree of tonal instability and tension. Vocalization is a common prehistoric root for speech and music. Its evolutionary bifurcation into speech and music has led to radically different principles of communication. While speech relies on the semantic certainty of words that can be translated into other languages with considerable precision, music deals with the emotional component of vocalization. The only similarity between speech and music can be found in the intonation of speech, which sharpens the meaning of words with the emotiondirected modulations of the voice.

When we see people talking passionately about something, this can stir our feelings. But in order to understand the monologues of Faust or Othello in the original languages, we need to understand the meaning of the words (in German and English, respectively) as well as the syntactic rules for using the words. As for music, it is the intuitively perceived gradient of tonal attraction that underlies music morphology and the conveyance of the meaning in music.

The hierarchy of discrete levels of tonal instability forms a frame of reference that allows the reading of melodic patterns and the perception of musical structures. In the European tradition, the musical system of reference is a seven-tone diatonic scale. Tones of a scale differ in pitch but this is less important than the difference in the degree of attraction to a tonal center of a scale, a tonic. Degrees of perceived tonal attraction generate a tonal space. In the process of listening to music, listeners' minds determine the status of each incoming musical sound in the tonal space by using the musical system of reference. The condition in which such an assessment of tonal status is not available is called amusia [59]. Whereas congenital (neurologically intact) amusics have a normal understanding of speech, the inability to create a mental musical system of reference prevents them from detecting musical structures in the tonal space. As a result, amusics are not able to detect musical content.

The tonal space is linear in the sense of sound frequency distribution (as on a piano keyboard), but it is nonlinear in the sense of tonal attraction [60]. 
Musical matter consists of the seven tones of a diatonic scale plus five chromatic tones. Moreover, musical matter is organized cyclically $[61,62]$ so that the same 12 semitones of the chromatic scale are repeated in different registers, thus creating a sound range (for example, the 88 sounds of a grand piano). The simplicity and economy of music matter is another factor explaining the broad accessibility of the language of music.

\section{Therapeutic properties of music}

The ability of music to activate the biological reward system and to arouse aesthetic emotions speaks for the therapeutic potential of music [63]. For example, for children with autism, music therapy helps to develop speech [64] and communication skills [65]. Melodic intonation therapy helps to restore speech in patients with Broca's aphasia [66].

One of the most obvious and at the same time enigmatic effects of music therapy can be observed in patients with Parkinson's disease when sounds of rhythmic music suddenly improve the patients' movements, as if the functioning of the complex neurobiological mechanisms of motor behavior, affected by the deficiency of dopaminergic neurons [67, 68], becomes "tuned" by the music. Moreover, rhythmic audio stimulation exercises lead to a sustained improvement in gait in patients with Parkinson's disease [69-71].

For stroke patients, listening to music improves both lexical memory and concentration of attention [72]; the improvement occurs along with subtle structural reorganization in the frontal-limbic region of the patients' brains.

Regular playing a musical instrument produces neuroplastic changes in white and gray matter in children and adults [63, 73-75). In children, the neuroplastic changes are accompanied by an improvement in the performance of memorization tasks $[76,77]$ that are correlated with the IQ. In older students, learning to play a musical instrument increases the level of visuomotor attention, improves motor functions, and positively affects the quality of life [78, 79].

One of the promising areas in the creation of rehabilitation systems that engage the resonant neurobiological feedback from the patient's natural oscillators is the use of music or music-like signals for controlled correction of functional states [80-85].

\section{Conclusion}

The melodic matter of music is distinguished by the simplicity and economy of its basic elements. Artistic arrangement of these elements into tonal-temporal structures creates images of complex psychological state - the virtual reality of emotions. Perceived tension, this intuitively sensed main morphological principle of the language of music, is linked to the motor system responses to the tense and not-tense musical compounds. The concept of perceived tonal tension comes to neuropsychology from music theory. It is the union of musicology and neuropsychology that allows researchers to study the behavioral and neurobiological correlates of emotional responsiveness to music. Music demonstrates therapeutic potential, the nature of which is not always clear. In addition, practicing a musical instrument and in some cases just listening to music can generate neuroplastic changes that correlate with improved cognitive and motor functions. These therapeutic effects establish music as an instrument of cognitive therapy.

Funding. The work was not funded.

Conflicts of interest. The author declares no conflict of interest.

\section{References}

1. Blood A.J., Zatorre R.J. Intensely pleasurable responses to music correlate with activity in brain regions implicated in reward and emotion. Proc Natl Acad Sci U S A 2001; 98(20): 11818-11823, https://doi.org/10.1073/pnas.191355898.

2. Berridge K.C., Kringelbach M.L. Pleasure systems in the brain. Neuron 2015; 86(3): 646-664, https://doi. org/10.1016/j.neuron.2015.02.018.

3. Panksepp J., Bernatzky G. Emotional sounds and the brain: the neuro-affective foundations of musical appreciation. Behav Processes 2002; 60(2): 133-155, https://doi. org/10.1016/s0376-6357(02)00080-3.

4. Sachs M.E., Ellis R.J., Schlaug G., Loui P. Brain connectivity reflects human aesthetic responses to music. Soc Cogn Affect Neurosci 2016; 11(6): 884-891, https://doi. org/10.1093/scan/nsw009.

5. Chanda M.L., Levitin D.J. The neurochemistry of music. Trends Cogn Sci 2013; 17(4): 179-93, https://doi.org/10.1016/j. tics.2013.02.007.

6. Bernardi L., Porta C., Sleight P. Cardiovascular, cerebrovascular, and respiratory changes induced by different types of music in musicians and non-musicians: the importance of silence. Heart 2005; 92(4): 445-452, https://doi.org/10.1136/ hrt.2005.064600.

7. Koelsch S., Siebel W.A. Towards a neural basis of music perception. Trends Cogn Sci 2005; 9(12): 578-584, https://doi.org/10.1016/j.tics.2005.10.001.

8. Iwanaga M., Moroki Y. Subjective and physiological responses to music stimuli controlled over activity and preference. J Music Ther 1999; 36(1): 26-38, https://doi. org/10.1093/jmt/36.1.26.

9. Krumhansl C.L. An exploratory study of musical emotions and psychophysiology. Can J Exp Psychol 1997; 51(4): 336-353, https://doi.org/10.1037/1196-1961.51.4.336.

10. Trappe H.-J. Music and medicine: the effects of music on the human being. Applied Cardiopulmonary Pathophysiology 2012; 16: 133-142.

11. Cannon W.B. Bodily changes in pain, hunger, fear and rage, an account of recent researches into the function of emotional excitement. New York and London: D. Appleton and Co.; 1915.

12. Ekman P., Cordaro D. What is meant by calling emotions basic. Emotion Review 2011; 3(4): 364-370, https:// doi.org/10.1177/1754073911410740. 
13. Solntsev V.M. K voprosu o semantike ili yazykovom znachenii (vmesto predisloviya). V kn.: Problemy semantiki [To the question of semantics or linguistic value (in lieu of a preface). In: Problems of semantics]. Moscow: Nauka; 1974.

14. Handbook of music and emotion: theory, research, applications. Juslin P.N., Sloboda J.A. (editors). New York: Oxford University Press; 2010.

15. Virtala P., Huotilainen M., Partanen E., Fellman V., Tervaniemi M. Newborn infants' auditory system is sensitive to Western music chord categories. Front Psychol 2013; 4: 492, https://doi.org/10.3389/fpsyg.2013.00492.

16. Granier-Deferre C., Bassereau S., Ribeiro A., Jacquet A.-Y., DeCasper A.J. A melodic contour repeatedly experienced by human near-term fetuses elicits a profound cardiac reaction one month after birth. PLoS One 2011; 6(2): e17304, https://doi.org/10.1371/journal.pone.0017304.

17. Trainor L.J. Are there critical periods for musical development? Dev Psychobiol 2004; 46: 262-278.

18. Costa-Giomi E. Young children's harmonic perception. Ann N Y Acad Sci 2003; 999: 477-484.

19. Korsakova-Kreyn M., Dowling W.J. Emotional processing in music: study in affective responses to tonal modulation in controlled harmonic progressions and real music. Psychomusicology: Music, Mind, and Brain 2014; 24(1): 4-20, https://doi.org/10.1037/pmu0000029.

20. Bigand E., Poulin-Charronnat B. Are we "experienced listeners"? A review of the musical capacities that do not depend on formal musical training. Cognition 2006; 100(1): 100-130, https://doi.org/10.1016/j.cognition.2005.11.007.

21. Panksepp J. Affective neuroscience: the foundations of human and animal emotions. New York: Oxford University Press; 1998.

22. Panksepp J. Affective consciousness: core emotional feelings in animals and humans. Conscious Cogn 2005; 14(1): 30-80, https://doi.org/10.1016/j.concog.2004.10.004.

23. MacLean P.D. The triune brain in evolution: role in paleocerebral functions. New York: Plenum Press; 1990.

24. MacLean P.D. Some psychiatric implications of physiological studies on frontotemporal portion of limbic system (visceral brain). Electroencephalogr Clin Neurophysiol 1952; 4(4): 407-418, https://doi.org/10.1016/0013-4694(52)90073-4.

25. Lerdahl F. Tonal pitch space. New York: Oxford University Press; 2001.

26. Lerdahl F., Krumhansl C.L. Modeling tonal tension. Music Perception: an Interdisciplinary Journal 2007; 24(4): 329-366, https://doi.org/10.1525/mp.2007.24.4.329.

27. Gagnon L., Peretz I. Mode and tempo relative contributions to "happy-sad" judgements in equitone melodies. Cogn Emot 2003; 17(1): 25-40, https://doi. org/10.1080/02699930302279.

28. Hevner K. Experimental studies of the elements of expression in music. Am J Psychol 1936; 48(2): 246, https:// doi.org/10.2307/1415746.

29. Kastner M.P., Crowder R.G. Perception of the major/ minor distinction: IV. Emotional connotations in young children. Music Perception: an Interdisciplinary Journal 1990; 8(2): 189201, https://doi.org/10.2307/40285496.

30. Trochidis K., Bigand E. Investigation of the effect of mode and tempo on emotional responses to music using EEG power asymmetry. J Psychophysiol 2013; 27(3): 142-148, https://doi.org/10.1027/0269-8803/a000099.

31. Virtala P., Tervaniemi M. Neurocognition of majorminor and consonance-dissonance. Music Perception: an
Interdisciplinary Journal 2017; 34(4): 387-404, https://doi. org/10.1525/mp.2017.34.4.387.

32. Webster G.D., Weir C.G. Emotional responses to music: interactive effects of mode, texture, and tempo. Motivation and Emotion 2005; 29(1): 19-39, https://doi.org/10.1007/s11031005-4414-0.

33. Firmino E.A., Bueno J.L.O., Bigand E. Effects of tonal modulation on subjective time estimation. Music Perception 2009; 26(3): 205-209.

34. Koelsch S., Gunter T., Schröger E., Friederici A.D. Processing tonal modulations: an ERP study. J Cogn Neurosci 2003; 15(8): 1149-1159, https://doi.org/10.1162/08989290332 2598111

35. Radchenko G.S., Parin S.B., Polevaya S.A., Korsakova-Kreyn M.N., Fedotchev A.I. EEG correlates of perception of tonal modulation in musical fragments. Int $J$ Psychophysiol 2014; 94(2): 192, https://doi.org/10.1016/j. ijpsycho.2014.08.798.

36. Thompson W.F., Cuddy L.L. Music performance and the perception of key. J Exp Psychol Hum Percept Perform 1997; 23(1): 116-35, https://doi.org/10.1037/0096-1523.23.1.116.

37. Tillmann B., Bharucha J.J., Bigand E. Implicit learning of tonality: a self-organizing approach. Psychol Rev 2000; 107(4): 885-913, https://doi.org/10.1037/0033-295x.107.4.885.

38. Fétis F.-J. Complete treatise on the theory and practice of harmony. Translated by Landey P.M. Hillsdale: Pendragon Press; 2008.

39. Meyer L.B. Emotion and meaning in music. Chicago, IL: University of Chicago Press; 1956.

40. Rosen C. Sonata forms. New York: W.W. Norton; 1988.

41. Schoenberg A. Structural functions of harmony. New York: W.W. Norton; 1969.

42. Korsakova-Kreyn M. Two-level model of embodied cognition in music. Psychomusicology: Music, Mind, and Brain 2018; 28(4): 240-259, https://doi.org/10.1037/pmu0000228.

43. Hepokoski J., Darcy W. Elements of sonata theory norms, types, and deformations in the late-eighteenth-century sonata. New York: Oxford University Press; 2006.

44. Sposobin I.V. Muzykal'naya forma [Musical form]. Moscow: Muzyka; 1984.

45. Scruton R. The aesthetics of music. New York: Oxford University Press; 1997.

46. Nielsen F.V. Oplevelse of musikalsk spænding [The experience of musical tension]. Copenhagen: Akademisk Forlag; 1983.

47. Madsen C.K., Fredrickson W.E. The experience of musical tension: a replication of Nielsen's research using the continuous response digital interface. J Music Ther 1993; 30(1): 46-63, https://doi.org/10.1093/jmt/30.1.46.

48. Williams L.R., Fredrickson W.E., Atkinson S. Focus of attention to melody or harmony and perception of music tension: an exploratory study. International Journal of Music Education 2011; 29(1): 72-81, https://doi. org/10.1177/0255761410372725.

49. Damasio A. The feeling of what happens: body and emotion in the making of consciousness. London: Heinemann; 1999.

50. Damasio A. Self comes to mind: constructing the conscious brain. New York: Pantheon Books; 2010.

51. Bidelman G.M., Krishnan A. Neural correlates of consonance, dissonance, and the hierarchy of musical pitch in the human brainstem. J Neurosci 2009; 29(42): 13165-13171, https://doi.org/10.1523/jneurosci.3900-09.2009. 
52. Bidelman G.M., Krishnan A. Brainstem correlates of behavioral and compositional preferences of musical harmony. NeuroReport 2011; 22(5): 212-326, https://doi.org/10.1097/ wnr.0b013e328344a689.

53. Ferrero G. L'inertie mentale et la loi du moindre effort [Mental inertia and the law of least effort]. Revue Philosophique de la France et de l'Étranger 1894; 37: 169-182.

54. Bowling D.L., Purves D. A biological rationale for musical consonance. Proc Natl Acad Sci U S A 2015; 112(36): 11155-11160, https://doi.org/10.1073/pnas.1505768112.

55. Helmholtz H.L.F. On the sensations of tone as a physiological basis for the theory of music. Translated by Ellis A.J. UK: Cambridge University Press; 2009, https://doi. org/10.1017/cbo9780511701801

56. Dassa A., Amir D. The role of singing familiar songs in encouraging conversation among people with middle to late stage Alzheimer's disease. J Music Ther 2014; 51(2): 131153, https://doi.org/10.1093/jmt/thu007.

57. Quintin E.-M., Bhatara A., Poissant H., Fombonne E., Levitin D.J. Emotion perception in music in high-functioning adolescents with autism spectrum disorders. J Autism Dev Disord 2010; 41(9): 1240-1255, https://doi.org/10.1007/ s10803-010-1146-0.

58. Langer S. Philosophy in a new key. A study in the symbolism of reason, rite, and art. Cambridge: Harvard University Press; 1942.

59. Peretz I., Vuvan D.T. Prevalence of congenital amusia. Eur J Hum Genet 2017; 25(5): 625-830, https://doi. org/10.1038/ejhg.2017.15.

60. Krumhansl C.L., Kessler E.J. Tracing the dynamic changes in perceived tonal organization in a spatial representation of musical keys. Psychol Rev 1982; 89(4): 334368, https://doi.org/10.1037/0033-295x.89.4.334.

61. Chew E. Mathematical and computational modeling of tonality: theory and applications. International Series in Operations Research \& Management Science. Springer US; 2014, https://doi.org/10.1007/978-1-4614-9475-1.

62. Purwins H., Blankertz B., Obermayer K. Toroidal models in tonal theory and pitch-class analysis. Computing in Musicology 2007; 15: 73-98.

63. Altenmüller E., Schlaug G. Apollo's gift: new aspects of neurologic music therapy. Prog Brain Res 2015; 217: 237-252, https://doi.org/10.1016/bs.pbr.2014.11.029.

64. Wan C.Y., Demaine K., Zipse L., Norton A., Schlaug G. From music making to speaking: engaging the mirror neuron system in autism. Brain Res Bull 2010; 82(3-4): 161-168, https://doi.org/10.1016/j.brainresbull.2010.04.010.

65. Kim J., Wigram T., Gold C. Emotional, motivational and interpersonal responsiveness of children with autism in improvisational music therapy. Autism 2009; 13(4): 389-409, https://doi.org/10.1177/1362361309105660.

66. Schlaug G., Marchina S., Norton A. Evidence for plasticity in white-matter tracts of patients with chronic Broca's aphasia undergoing intense intonation-based speech therapy. Ann N Y Acad Sci 2009; 1169(1): 385-394, https://doi. org/10.1111/j.1749-6632.2009.04587.x.

67. Parker N.F., Cameron C.M., Taliaferro J.P., Lee J., Choi J.Y., Davidson T.J., Daw N.D., Witten I.B. Reward and choice encoding in terminals of midbrain dopamine neurons depends on striatal target. Nat Neurosci 2016; 19(6): 845-854, https://doi.org/10.1038/nn.4287.

68. Xu Z., Chu X., Jiang H., Schilling H., Chen S., Feng J. Induced dopaminergic neurons: a new promise for
Parkinson's disease. Redox Biol 2017; 11: 606-612, https:// doi.org/10.1016/j.redox.2017.01.009.

69. Ashoori A., Eagleman D.M., Jankovic J. Effects of auditory rhythm and music on gait disturbances in Parkinson's disease. Front Neurol 2015; 6: 234, https://doi.org/10.3389/ fneur.2015.00234.

70. Bukowska A.A., Krężałek P., Mirek E., Bujas P., Marchewka A. Neurologic music therapy training for mobility and stability rehabilitation with Parkinson's disease - a pilot study. Front Hum Neurosci 2016; 9: 710, https://doi. org/10.3389/fnhum.2015.00710.

71. Pau M., Corona F., Pili R., Casula C., Sors F., Agostini T., Cossu G., Guicciardi M., Murgia M. Effects of physical rehabilitation integrated with rhythmic auditory stimulation on spatio-temporal and kinematic parameters of gait in Parkinson's disease. Front Neurol 2016; 7: 126, https:// doi.org/10.3389/fneur.2016.00126.

72. Särkämö T., Tervaniemi M., Laitinen S., Forsblom A., Soinila S., Mikkonen M., Autti T., Silvennoinen H.M., Erkkilä J., Laine M., Peretz I., Hietanen M. Music listening enhances cognitive recovery and mood after middle cerebral artery stroke. Brain 2008; 131(3): 866-876, https://doi.org/10.1093/ brain/awn013.

73. Gaser C., Schlaug G. Brain structures differ between musicians and non-musicians. J Neurosci 2003; 23(27): 92409245.

74. Hyde K.L., Lerch J., Norton A., Forgeard M., Winner E., Evans A.C., Schlaug G. Musical training shapes structural brain development. J Neurosci 2009; 29(10): 3019-3025, https://doi.org/10.1523/jneurosci.5118-08.2009.

75. Wan C.Y., Schlaug G. Music making as a tool for promoting brain plasticity across the life span. Neuroscientist 2010; 16(5): 566-577, https://doi.org/10.1177/ 1073858410377805.

76. Schellenberg E.G. Music lessons enhance IQ. Psychological Science 2004; 15(8): 511-514, https://doi. org/10.1111/j.0956-7976.2004.00711.x.

77. Forgeard M., Winner E., Norton A., Schlaug G. Practicing a musical instrument in childhood is associated with enhanced verbal ability and nonverbal reasoning. PLoS One 2008; 3(10): e3566, https://doi.org/10.1371/journal.pone.0003566.

78. Bugos J.A., Perlstein W.M., McCrae C.S., Brophy T.S. Bedenbaugh P.H. Individualized piano instruction enhances executive functioning and working memory in older adults. Aging Ment Health 2007; 11(4): 464-471, https://doi. org/10.1080/13607860601086504.

79. Seinfeld S., Figueroa H., Ortiz-Gil J., Sanchez-Vives M.V. Effects of music learning and piano practice on cognitive function, mood and quality of life in older adults. Front Psychol 2013; 4: 810, https://doi.org/10.3389/ fpsyg.2013.00810.

80. Fedotchev A.I., Oh S.J., Semikin G.I. Combination of neurofeedback technique with music therapy for effective correction of stress-induced disorders. Sovremennye tehnologii $v$ medicine 2014; 6(3): 60-63.

81. Fedotchev A.I., Bondar' A.T., Bakhchina A.V., Parin S.B., Polevaya S.A., Radchenko G.S. Effects of music-acoustic signals, online controlled by EEG oscillators of the subject. Rossiiskii fiziologicheskii zhurnal imeni I.M. Sechenova 2015; 101(8): 970-977.

82. Fedotchev A.I., Bondar A.T., Bakhchina A.V., Grigorieva V.N., Katayev A.A., Parin S.B., Radchenko G.S., Polevaya S.A. Transformation of patient's EEG oscillators into 
music-like signals for correction of stress-induced functional states. Sovremennye tehnologii v medicine 2016; 8(1): 93-98, https://doi.org/10.17691/stm2016.8.1.12.

83. Fedotchev A.I., Bondar' A.T., Bakhchina A.V., Parin S.B., Polevaya S.A., Radchenko G.S. Music-acoustic signals controlled by subject's brain potentials in the correction of unfavorable functional states. Uspekhi fiziologicheskikh nauk 2016; 47(1): 69-79.

84. Fedotchev A.I., Zhuravlev G.I., Eksina K.I.,
Silantieva O.M., Polevaya S.A. Evaluation of efficiency of musical EEG neurointerface with additional control contour from heart rhythm. Rossiiskii fiziologicheskii zhurnal imeni I.M. Sechenova 2018; 104(1-12): 122-128.

85. Zemlyanaya A.A., Radchenko G.S., Fedotchev A.I. Music therapy procedures controlled by the brain potentials in treatment of functional disorders. Zhurnal nevrologii $i$ psihiatrii imeni S.S. Korsakova 2018; 118(3): 103, https://doi. org/10.17116/jnevro201811831103-106. 